\title{
Análises multidimensional e Bakhtiniana do discurso de trabalhos de conclusão desenvolvidos no âmbito de um mestrado profissional em ensino de Física
}

\author{
Multidimensional and Bakhtinian discourse analysis \\ of dissertations designed in the context of a professional \\ master's degree in Physics education
}

Matheus Monteiro Nascimento ${ }^{1}$. Fernanda Ostermann ${ }^{1}$. Cláudio Cavalcanti ${ }^{1}$

\begin{abstract}
Resumo: Neste artigo analisamos a influência do contexto de formação de um curso de Mestrado Profissional em Ensino de Física (MPEF) no desenvolvimento de seus produtos educacionais. A pesquisa consiste de uma análise quantitativa e de uma análise discursiva dos produtos desenvolvidos na forma de textos de apoio de Física clássica. A análise quantitativa indicou que a maneira como os autores dos produtos educacionais encaram os referenciais teóricos sinaliza uma concepção ingênua em relação à necessidade dessa fundamentação nos seus trabalhos. A análise discursiva evidenciou aspectos semelhantes. Poucas vezes identificamos uma articulação entre o aporte teórico, as questões-foco, o desenvolvimento, a aplicação e a avaliação do produto. Notamos que o racionalismo técnico propagado pelo curso sustenta o desenvolvimento dos produtos, influenciando tanto nas suas direcionalidade, responsividade e expressividade quanto no gênero discursivo dos trabalhos. Achados indicam também que os produtos educacionais desenvolvidos tendem a ser pouco relevantes frente às necessidades escolares.
\end{abstract}

Palavras-chave: Mestrado profissional. Ensino de física. Produto educacional. Análise multidimensional.

\begin{abstract}
In this work we analyze the influence of the Professional Master's degree in the Physics Teaching (PMPT) training context on the development of educational products. The research consists in a quantitative analysis and a discursive analysis of Classical Physics didactical texts. Quantitative analysis indicated that the way the authors of educational products treat theoretical frameworks points to a naive belief in the need of a solid theoretical foundation in their works. The discursive analysis showed similar aspects. A few times, we identified links between the theoretical contribution, focus-issues, development, implementation and evaluation of educational products. We note that the technical rationality disseminated through the course environment directly influences the development of educational products, reflecting the directionality, responsiveness, expressiveness and speech genre present on these works. Educational products developed tend to be of little relevance for the needs of school.
\end{abstract}

Keywords: Professional Master's degree. Physics teaching. Educational product. Multidimensional scaling.

\footnotetext{
${ }^{1}$ Universidade Federal do Rio Grande do Sul (UFRGS), Instituto de Física, Porto Alegre, RS, Brasil. E-mail:

<matheus.monteiro@ufrgs.br>.
} 


\section{Introdução}

No Brasil, o sistema de pós-graduação é dividido em quatro modalidades de cursos diferentes: doutorado, mestrado, especialização e aperfeiçoamento. Essa estrutura tem sido influenciada por agendas de organismos internacionais, como a Organização de Cooperação e Desenvolvimento Econômico (OCDE), que coloca a educação como um dos motores do crescimento econômico, necessitando aproximá-la do modelo empresarial para que corresponda à lógica do mercado (REZENDE; OSTERMANN, 2015). Cada uma dessas etapas da pós-graduação possui definições e características próprias. O mestrado é ainda subdividido em duas modalidades, denominadas acadêmico e profissional. O mestrado acadêmico (MA) é definido como sendo uma preparação para o doutorado, no qual o aluno deve apropriar-se da literatura científica da área e participar de atividades de pesquisa relacionadas (QUELHAS; FARIA FILHO; FRANÇA, 2005). Já o mestrado profissional (MP) é um mestrado stricto sensu e segue as diretrizes da Portaria Normativa no 17, de 28 de dezembro de 2009 da Coordenação de Aperfeiçoamento de Pessoal de Nível Superior (CAPES, 2009), diferentemente da modalidade acadêmica de Mestrado. O MP teve sua regulamentação aprovada em 1995, mas somente a partir da Portaria $n^{\circ} 80$, promulgada em 1996 é que teve o reconhecimento da CAPES (CAPES, 1999). Essa modalidade surge a partir da necessidade de desenvolvimento da pós-graduação profissional no país e busca aproximar os trabalhos produzidos na universidade das demandas sociais e profissionais (QUELHAS; FARIA FILHO; FRANÇA, 2005). Dessa forma, o mestrado profissional "[...] objetiva a capacitação para a prática profissional transformadora com foco na gestão, produção ou aplicação do conhecimento, visando à solução de problemas ou proposições de inovações [...]" (CAPES, 2008, p. 1).

Desde a sua criação, o MP passou a atrair a atenção de diversos setores sociais, havendo uma significativa expansão no número de cursos reconhecidos. De acordo com o portal da CAPES, em 1998 havia 24 cursos aprovados no país e, atualmente, são 579 recomendados e reconhecidos. Essa ampliação teve forte impacto na área de Ensino de Ciências e Matemática, que hoje conta com 48 cursos de mestrado acadêmico e 66 de mestrado profissional. Além disso, em 2012, foi criado o Mestrado Nacional Profissional em Ensino de Física (MNPEF) pela Sociedade Brasileira de Física, que hoje conta com 63 polos espalhados pelo país.

Resultados de pesquisa indicam que cursos de MP em Ensino, que possuem estrutura curricular com ênfase em disciplinas específicas e no uso de novas tecnologias no ensino, não conseguem produzir os efeitos esperados. Shaffer e Ostermann (2013) afirmam que a prática pedagógica dos professores da educação básica, ingressantes no MP, está repleta de elementos do racionalismo técnico, desde a questão curricular, planejamento, crenças e concepções, os quais o curso de MP não parece abalar. Rezende e Ostermann (2015) assinalam que este resultado se deve ao fato da estrutura curricular do curso ser elaborada por especialistas acadêmicos, que geralmente não se atentam às reais demandas da escola ou do professor. Com base nessas colocações, afirmamos que nosso trabalho não está procurando elementos que reafirmem o modelo de formação do MPEF. Pelo contrário, estamos preocupados em investigar as influências do paradigma da racionalidade técnica nos trabalhos de conclusão dos alunos-professores².

\footnotetext{
${ }^{2}$ Aluno-professor é o nome atribuído aos estudantes do MPEF, pois estudam e lecionam simultaneamente.
} 
Essa investigação se faz relevante na medida em que, para a CAPES, um dos critérios de avaliação de um MP é o potencial de transferência e de aplicabilidade do produto educacional (PE) em sistemas educativos. Nossa pesquisa se propõe a analisar produtos educacionais, juntamente com elementos da dissertação, produzidos por um curso de Mestrado Profissional em Ensino de Física (MPEF). Nossa análise constitui-se de duas etapas: a primeira quantitativa, analisando o universo total de produtos desenvolvidos; e a segunda, uma análise discursiva dos produtos de natureza texto de apoio, com foco na Física clássica. A ideia é que essas duas análises se complementem e que aspectos relevantes observados a partir de uma investigação estatística possam ser integrados a uma análise de discurso.

\section{Análise dos referenciais teóricos}

Tendo em mãos as 91 dissertações concluídas entre 2002 e 2014, buscamos investigar um ponto de muita discussão no cenário dos cursos de MP: o papel do referencial teórico na elaboração dos trabalhos de conclusão. Um primeiro aspecto é o das especificidades da utilização desses referenciais em projetos de pesquisa e de desenvolvimento. Para Ostermann e Rezende (2009), os projetos de pesquisa utilizam os referenciais para elaborar as questões de pesquisa e precisam ser integrados com a metodologia, enquanto que nos projetos de desenvolvimento eles devem fundamentar metodologias de ensino e orientar a escolha dos conteúdos, além de estabelecer novas formas de avaliação, ou seja, sustentar toda a elaboração do produto educacional. A forma como os referenciais teóricos são tratados nos trabalhos de conclusão é um importante elemento que permite vislumbrar a perspectiva de formação que permeia o referido curso de Mestrado Profissional, bastante próxima da racionalidade técnica (SCHÄFER, 2013; SOUZA, 2015).

No sentido de quantificar o problema central da análise - o tratamento dado aos referenciais teóricos dos trabalhos de conclusão - o presente estudo assume que dois diferentes autores são considerados pelos alunos-professores (e respectivos orientadores) como similares quando são adotados em conjunto no trabalho, sem que uma argumentação teoricamente fundamentada e convincente justifique a possibilidade de articulação entre as ideias defendidas por esses autores. A ideia de similaridade que está sendo proposta pressupõe que o aluno-professor se alinha ativamente às seguintes posturas: (1) que há possibilidade de integração entre as teorias de distintos autores; (2) que as diferenças entre pressupostos importantes nas diversas teorias não são importantes a ponto de serem consideradas nos trabalhos e, por fim; (3) que o referencial teórico pode ser um instrumento no trabalho, mais do que uma fundamentação teórica. Assim, mesmo que não haja uma posição explícita na dissertação em favor da similaridade entre autores adotados no respectivo referencial teórico, supõe-se que a simples justaposição, ou uma tentativa mal fundamentada de articulação entre diferentes autores no referencial teórico do trabalho, constitui-se em um alinhamento a uma posição axiológica que assume uma similaridade implícita entre eles.

Para quantificar essas similaridades, construiu-se uma tabela cujas linhas são os autores dos referenciais teóricos adotados em cada um dos trabalhos (codificados de modo que seja possível sua identificação posterior) e as colunas são os trabalhos. Foram pesquisados todos os autores presentes em todos os referenciais teóricos, desconsiderando autores que embasavam 
referenciais metodológicos ou autores que eram citados esporadicamente (por exemplo, para explicar conceitos específicos tratados nos trabalhos). Nessa tabela foi atribuído o valor 0 quando o autor não estava presente no referencial teórico e 1 quando estava presente, configurando uma tabela com dados do tipo presença/ausência para cada autor ${ }^{3}$. Assim, cada autor é descrito por uma sequência de 0 e 1 , a partir da qual se pode calcular a dissimilaridade, que mantém relação próxima com a similaridade ${ }^{4}$. A medida de dissimilaridade adotada foi a dissimilaridade de Jaccard (MYATT; JOHNSON, 2014, p. 92-93), bastante apropriada para dados binários (nesse caso, as coincidências de 0 não são levadas em conta, ou seja, dois autores não são considerados similares pelas suas ausências simultâneas nos trabalhos, mas sim pelas presenças simultâneas nos mesmos).

A partir dessas dissimilaridades foi feita uma Análise Multidimensional (Multidimensional Scaling - MDS). A principal meta da MDS é visualizar em um plano bidimensional (ou em mais dimensões) similaridades entre casos no contexto dos 91 trabalhos. Em nosso trabalho foi utilizada a Análise Multidimensional não-Métrica (Non-Metrical Multidimensional Scaling - NMDS), que propõe uma abordagem distinta. A diferença entre a MDS métrica e não métrica reside no fato de que a não métrica organiza o mapa por ordem, não propriamente pelos valores absolutos das dissimilaridades. Em outras palavras, está se assumindo que as dissimilaridades entre os trabalhos mantêm uma relação monotônica com as dissimilaridades calculadas e obtidas dos dados, ou seja, maiores dissimilaridades levam a maiores distâncias no mapa obtido, mas sem reproduzir necessariamente as mesmas dissimilaridades iniciais. Assim, o mapa feito por MDS não métrica tentará reproduzir não as dissimilaridades em si, mas a ordem dessas dissimilaridades.

É nesse sentido que a MDS não métrica tende a organizar o mapa por ordenamento e não por valor absoluto de dissimilaridade. Para isso, usa-se um tipo de regressão não paramétrica, chamada regressão isotônica (BORG; GROENEN; MAIR, 2013; COX; COX, 2001), diferente da regressão paramétrica utilizada na MDS métrica. Esse tipo de MDS é mais adequada para o presente caso, que visa investigar similaridades implícitas na adoção de referenciais teóricos em diversos trabalhos ${ }^{5}$, além de ser menos restritivo do que a MDS métrica e, por isso, levar a um ajuste mais interessante em alguns casos. Para melhorar o ajuste e obter resultados mais consistentes, optou-se por rodar a NMDS em três dimensões, representando a terceira coordenada por cores nos pontos, como pode ser visto na Figura 1. A quantidade denominada stress, dá uma medida de quão bom foi o ajuste dos pontos no mapa, tanto na MDS métrica ou não

\footnotetext{
${ }^{3}$ Em todos os 91 trabalhos foram encontrados 15 autores distintos. Duas outras designações foram também consideradas: um trabalho em que o aluno-professor declara sua vivência docente como o referencial teórico denominado como Próprio - mais dois trabalhos nos quais o referencial teórico não foi definido - designados como ND (Não Definido).

${ }^{4}$ Uma possível relação entre a dissimilaridade $d$ e a similaridade $s$ é $d=1-s$.

${ }^{5}$ Essa dissimilaridade entre autores não pode ser quantificada exatamente, mas pode ser ordenada - se em três trabalhos $\mathrm{A}, \mathrm{B}$ e $\mathrm{C}$ a dissimilaridade entre $\mathrm{A}$ e $\mathrm{B}$ é maior do que entre $\mathrm{A}$ e $\mathrm{C}$, o máximo que se pode dizer é que $\mathrm{A}$ é mais similar a $\mathrm{B}$ do que a $\mathrm{C}$.
} 
métrica. O valor 0,0143 corresponde a um ajuste excelente (LEVSHINA, 2015). A interpretação do mapa é simples: maior a proximidade entre os pontos (autores), maior a similaridade. Se dois autores fossem sempre adotados em conjunto nos referenciais teóricos de um certo grupo de trabalhos, sem que cada um seja adotado individualmente em nenhum outro trabalho, eles apareceriam como totalmente similares no mapa, ou seja, ocupariam exatamente o mesmo ponto.

Figura 1. Mapa produzido pela NMDS das dissimilaridades de Jaccard entre os autores adotados nos referenciais teóricos dos 91 trabalhos
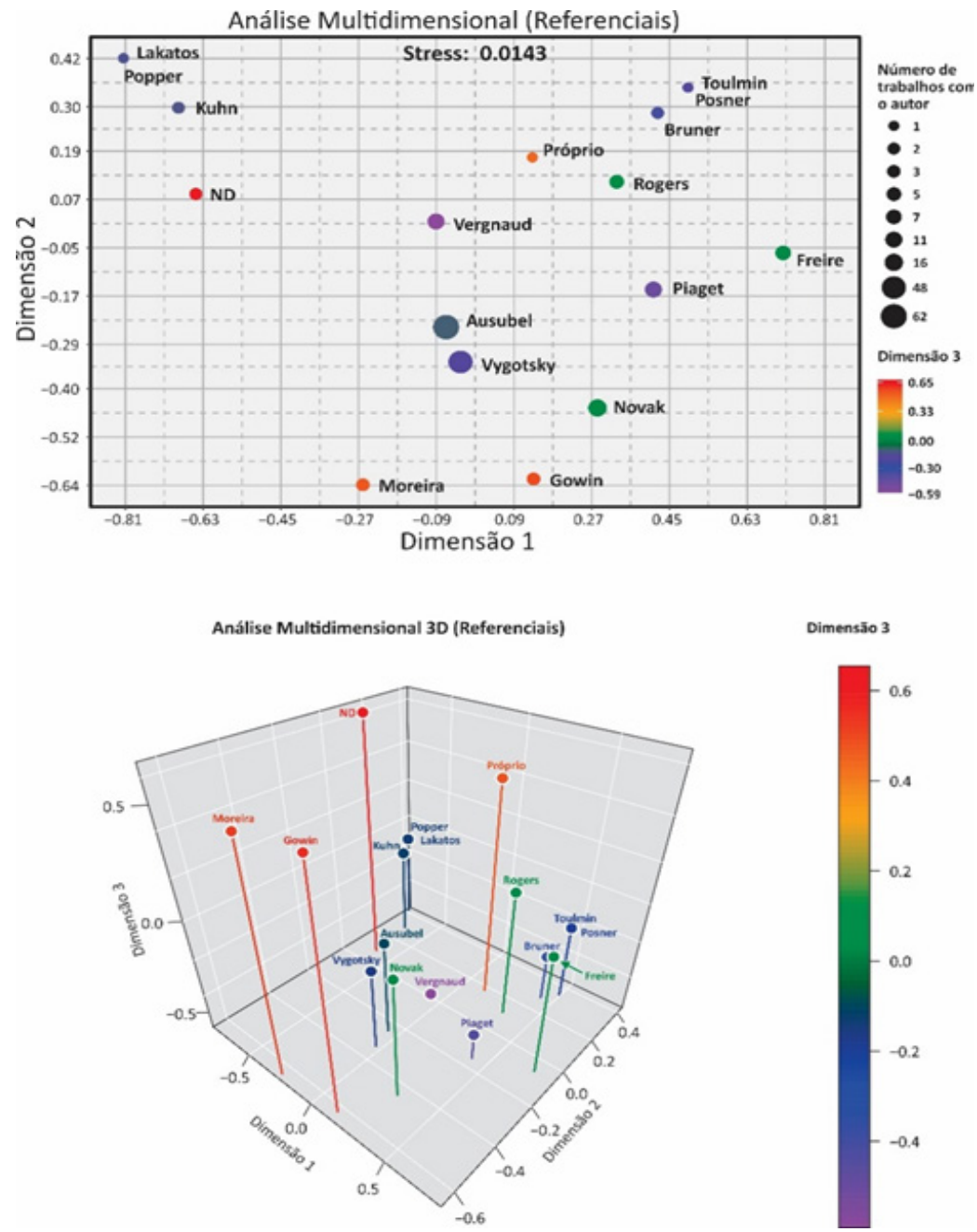

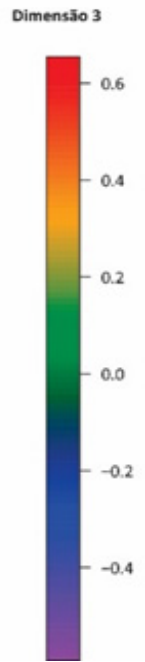

O mapa superior é a projeção bidimensional e o mapa inferior o gráfico tridimensional. Os autores adotados em maior número nos referenciais dos trabalhos de conclusão aparecem mais nas regiões centrais do mapa, sendo as regiões periféricas ocupadas pelos autores mais raramente adotados. As escalas coloridas ao lado dos gráficos são usadas para designar a coordenada da terceira dimensão, cuja direção é perpendicular às dimensões 1 e 2 (valores mais baixos perto de lilás e valores mais altos perto do vermelho). Assim, os pontos não estão contidos no plano (gráfico superior), mas em diferentes "alturas". A legenda contendo a escala de tamanhos identifica o número de trabalhos nos quais cada autor é adotado como referencial teórico.

Fonte: Elaborado pelos autores. 
Como se pode ver na Figura 1, a similaridade mais pronunciada se dá entre Vygotsky e Ausubel, já que são os pontos mais próximos entre si no mapa. Há também uma alta similaridade implícita assumida entre os autores do grupo Vygotsky-Ausubel-Novak, embora Novak claramente esteja posicionado mais alto no mapa (coordenada da dimensão 3 maior) - isso fica claro no gráfico tridimensional na parte inferior da Figura 1. A similaridade obtida entre Vygotsky e Novak é ligeiramente maior do que entre Ausubel e Novak, o que é interessante, já que uma integração entre Ausubel e Novak é teoricamente coerente, mas entre ele e Vygotsky não se pode justificar tamanha aproximação. Sutilezas como essa não podem ser previstas apenas inspecionando os dados brutos (dissertações). Considerando a presença de Vygotsky no grupo Vygotsky-Ausubel-Novak, um autor não cognitivista e cuja teoria tem objetivos e bases epistemológicas bem distintas dos outros dois, essa similaridade que resulta da análise é problemática. A Figura 2 apresenta as similaridades finais ${ }^{6}$ a partir de uma análise de redes. Como afirmamos anteriormente, a maior similaridade se dá entre Vygotsky e Ausubel $(0,93)$ e a similaridade final entre Vygotsky e $\operatorname{Novak}(0,76)$ é ligeiramente maior do que entre Ausubel e Novak. Nota-se ainda que entre Kuhn e o grupo Popper-Lakatos existe uma similaridade alta. No entanto, essa similaridade se origina de apenas um trabalho, não sendo, portanto, representativa no contexto geral.

Figura 2. Gráfico de rede mostrando o mesmo layout dos pontos no plano das dimensões 1 e 2 da Figura 1

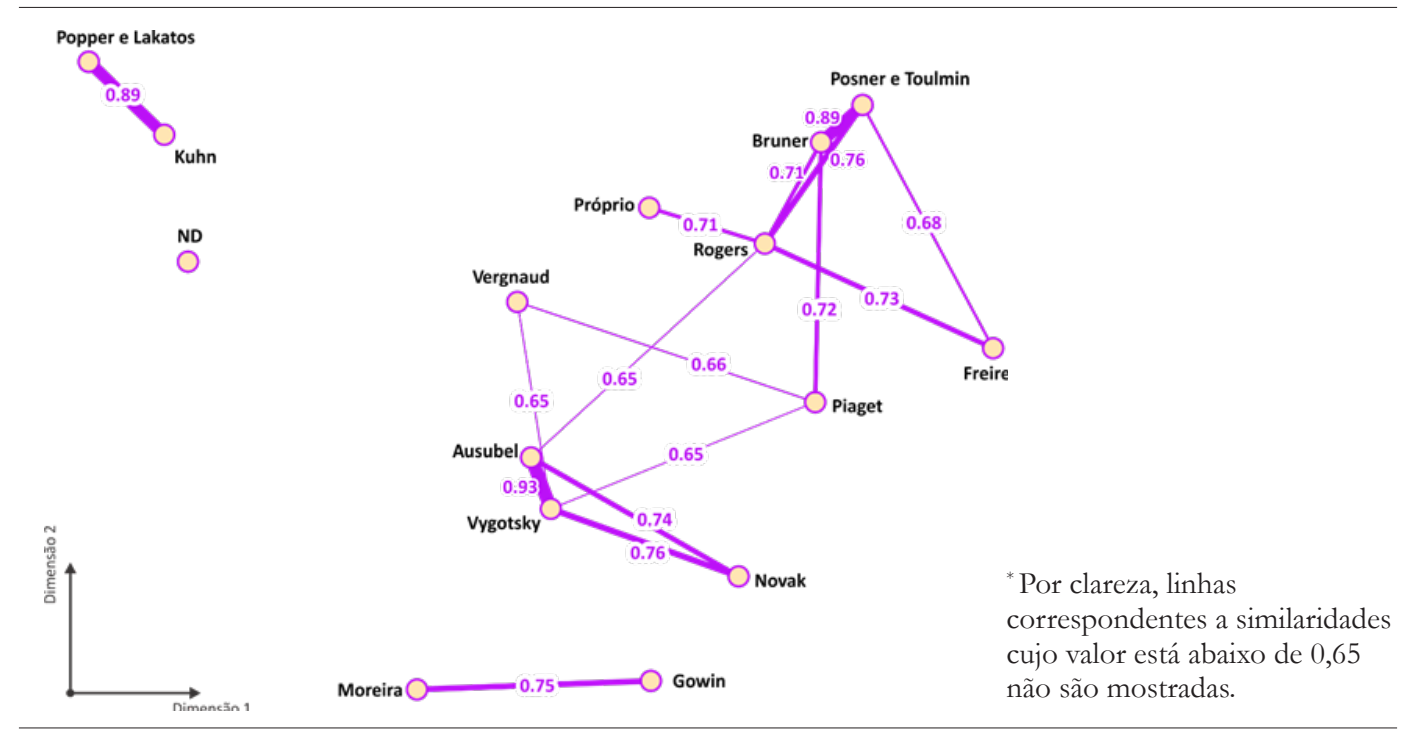

Fonte: Elaborado pelos autores.

\footnotetext{
${ }^{6}$ As similaridades finais são armazenadas em uma matriz S(i,j), obtida por transformação da matriz de distâncias euclidianas $D(i, j)$ entre dois pontos $i, j$ (no caso, autores presentes nos referenciais teóricos) da configuração final dos pontos no mapa, obtida após realizado o processo de NMDS. Sendo a similaridade obrigatoriamente limitada entre 0 (totalmente dissimilar) e 1 (totalmente similar), é necessário normalizar a 1 a matriz $D(i, j)$. Como $0 \leq$ $D(i, j) \leq d_{\max }$, onde $d_{\max }$ é o valor da distância euclidiana entre os dois pontos mais afastados do mapa, a matriz de dissimilaridades $D(i, j)$ é obtida da matriz de distâncias euclidianas simplesmente fazendo-se $D(i, j)=D(i, j) / d_{\max }$. A matriz de similaridades finais é então obtida fazendo-se $S(i, j)=1-D(i, j)=1-D(i, j) / d_{\max }$.
} 
O resultado dessas análises sinaliza que o contexto que permeia o Mestrado Profissional em Ensino de Física estudado está longe de ser de uma efetiva pesquisa aplicada. Na realidade, a utilização de referenciais simpáticos aos orientadores reforça a significação social e hierárquica do contexto extraverbal dos enunciados. Ou seja, a escolha desses aportes teóricos pode ser uma estratégia discursiva para estreitar a relação entre o aluno, o professor orientador e os avaliadores. Isso se justifica pelo fato de não observarmos, na maioria das vezes, uma relação entre o marco teórico e o produto desenvolvido.

A forma como muitos alunos-professores e seus respectivos orientadores encaram os referenciais teóricos indica que não dão a devida importância ao mesmo. Ocorrem diversas incoerências como a adoção de duplas de autores como Vygotsky e Piaget, ou Vygotsky e Ausubel, sem uma mínima reflexão a respeito dos pressupostos teóricos defendidos por eles. Isso é fruto do contexto diretivo que supervaloriza a produção de material didático (entre os quais o produto educacional) e sua decorrente aplicação na escola ${ }^{7}$, mais do que qualquer outro aspecto. Observamos que houve uma permissividade geral que incentivou a supervalorização de uma elaboração ateórica do produto, sem que os alunos-professores refletissem sobre as inconsistências teóricas advindas da simples justaposição de diferentes autores nos referenciais teóricos dos referidos trabalhos. Um fato que agrava a questão é a existência de uma disciplina de Teorias de Aprendizagem, justamente destinada a trabalhar com diferentes autores como Vygotsky, Ausubel, Piaget e outros - que, em geral, concentra-se nos mais clássicos, mas aborda outros não tão conhecidos. Parece não haver uma reflexão mínima a respeito da consistência dos referenciais teóricos, mesmo sendo ofertadas disciplinas para esse fim. Assim, se dois autores estão presentes em um dado referencial teórico, daí decorre uma posição axiológica do aluno-professor (e orientador), perspectiva que também foi reforçada pelo contexto de produção - ou contexto extraverbal - que se alinha a essa posição axiológica nas disciplinas e referências bibliográficas privilegiadas ao longo do curso.

É fato conhecido que vários dos trabalhos têm referenciais teóricos totalmente desarticulados da proposta de ensino (na qual está integrado o produto educacional). Por exemplo, no ano de criação do MPEF aqui investigado, Greca (2002), ao analisar trabalhos apresentados em um evento do Ensino de Ciências, já denunciava que poucos desses trabalhos se preocupavam em explicitar a relação do referencial teórico com o objeto de estudo. Essa desarticulação leva a crer que em nenhum momento nesse tipo de trabalho foi feita uma reflexão aprofundada sobre as diversas teorias elaboradas por esses teóricos, sobre suas bases epistemológicas, ou sobre as tensões ou possíveis convergências entre elas. Apesar de existir uma disciplina específica que deveria ter esse fim, parece que tal disciplina cumpriu apenas um papel meramente informativo sobre aspectos mais superficiais dessas diversas teorias. É natural, portanto, que os alunos-professores considerem adequado simplesmente justapor diversos teóricos no mesmo trabalho, justificando, boa parte das vezes, implicitamente, a ideia de que essa simples justaposição sustenta uma possível multiplicidade metodológica em sala de aula, na qual tomam-se elemen-

\footnotetext{
${ }^{7}$ Feita, de modo geral, sem que se leve em conta as necessidades escolares, em uma perspectiva formativa que se aproxima da concepção de especialista técnico (SOUZA, 2015).
} 
tos importantes de cada teoria que possam contribuir com o desenvolvimento de estratégias didáticas variadas. É exatamente nesse ponto que é adequado definir a metáfora do mercado, que consiste no seguinte (em linhas gerais):

[...] há pesquisadores que se apropriam superficialmente dos referenciais, centrando-se somente em seus conceitos-chave e empregando-os sem nenhum cuidado com a visão de mundo na qual tais conceitos foram cunhados [...]. Um outro problema é a combinação mais ou menos gratuita de conceitos originados em visões de mundo distintas - às vezes incompatíveis. Raramente são apresentados argumentos que sustentem a combinação teórica adotada. Tais como produtos no mercado, os conceitos científicos vão da prateleira para o carrinho de uma forma mais ou menos arbitrária. $\mathrm{O}$ critério que orienta sua escolha não é a coerência filosófica do conjunto, mas a utilidade de cada um e o gosto do autor (LIMA JÚNIOR et al., 2008, p. 3).

Em muitos casos isso também decorre de uma confusão entre teoria (que deve fundamentar uma multiplicidade metodológica no ensino) e metodologia de ensino, ou seja, uma falta de compreensão do que vem a ser um referencial teórico. Em outras ocasiões ocorre a simples citação a esmo de diferentes autores, dando a entender que o referencial teórico foi inserido no trabalho quase como uma obrigação normativa para a redação do trabalho acadêmico, não se estabelecendo nenhuma relação formal entre esse referencial e a concepção e desenvolvimento do produto educacional (e com a estratégia desenvolvida para sua introdução na escola). O objetivo acaba sendo desenvolver o produto a qualquer custo, reduzindo-se os objetivos desse tipo de mestrado a um patamar meramente técnico em que os alunos-professores executam tarefas concebidas em um contexto bastante diretivo, exatamente como um racionalista técnico. E, como um típico técnico, diversos aspectos das teorias de diferentes teóricos são trazidos do "mercado" para auxiliá-lo na sua tarefa, com extirpações e apropriações acríticas como se essas teorias fossem meras ferramentas que pudessem se complementar facilmente na realização das tarefas.

Esse viés quase mecânico, como uma linha de produção em chão de fábrica, influencia o ambiente de elaboração do produto educacional. É o contexto institucional, e em maior escala o contexto nacional em que as políticas de formação docente são elaboradas, que contribuem para a supervalorização da simples elaboração ateórica do produto educacional, seguido de aplicação sistemática e também ateórica em sala de aula. Por trás disso está subjacente uma concepção ingênua de pesquisa aplicada, considerando como tal a simples adoção de um produto educacional em sala de aula. Reforça-se assim, com a metáfora do mercado na elaboração de referenciais teóricos e a supervalorização do produto educacional, a visão do professor como tarefeiro que segue receitas concebidas por outras pessoas, que apoiam (ou pelo menos não polemizam) vozes que se aliam ao paradigma da racionalidade técnica. A simples constatação de que a maior similaridade implícita entre autores se dá entre Vygotsky e Ausubel, autores que propuseram teorias com pressupostos muito distintos, mostra o quanto os docentes do programa foram lenientes quanto à concepção formativa que estava em voga, o que transformou os trabalhos em meros veículos de confecção de produtos educacionais sem base teórica e cuja contribuição para a área de Ensino de Física é questionável, mesmo que esses produtos sejam pretensamente destinados ao ensino da Física nas escolas. Após a análise dos referenciais 
teóricos concluímos que, em geral, seu principal papel no desenvolvimento dos produtos é ajudar a construir uma estratégia discursiva para satisfazer demandas de docentes, orientadores e banca avaliadora. Parece que o curso do MP investigado não difunde a concepção de que, como apontam Ostermann e Rezende (2009), os produtos devem ser produzidos, implementados e avaliados à luz de referenciais teóricos atuais sobre ensino, aprendizagem e avaliação.

Na próxima seção vamos focar nosso olhar mais detalhadamente sobre um tipo de produto que se destacou dentro do universo de trabalhos: os textos de apoio de Física clássica. Do total de produtos educacionais desenvolvidos pelos estudantes do curso de MP estudado (91 trabalhos), 53 por cento são de natureza texto de apoio. Dentro dos textos de apoio, ainda, mais de 80 por cento abordam a Física Clássica. Vamos tentar, a partir de uma análise dialógica com os preceitos do Círculo Bakhtin/Voloshinov/Medvedev, encontrar nesses textos de apoio os elementos destacados nessa seção de forma quantitativa.

\section{Análise bakhtiniana do discurso}

Do universo de trabalhos concluídos no MPEF no período analisado, 28 se enquadravam dentro dos objetivos da pesquisa. Desses, apenas um deles não possuía produto educacional nem dissertação disponível no site da instituição, com isso, o escopo de nossa análise discursiva se constitui por 27 textos de apoio de Física clássica.

Além das particularidades que constituem o enunciado concreto ${ }^{8}$, elegemos outros conceitos da obra do Círculo para nos auxiliarem na análise dos textos de apoio, são eles: gênero do discurso, tema, estilos e entonação. Bakhtin (2011) entende que os enunciados refletem as condições específicas e as finalidades de cada campo da comunicação social. Deste modo, cada um dos tipos de comunicação social - como as relações de produção, de negócio, artísticas, cotidianas e ideológicas (VOLOSHINOV, 1981) - elabora seus tipos relativamente estáveis e particulares de enunciados, denominados gêneros do discurso. Os gêneros do discurso são compostos por um conteúdo temático (tema), um estilo de linguagem (estilo) e uma construção composicional. O tema é uma propriedade que pertence a cada enunciado como um todo; ele expressa a situação concreta que deu origem a esse enunciado. $\mathrm{O}$ tema de um enunciado é sempre escolhido visando a ideia que o autor quer passar para o suposto destinatário. Já o estilo linguístico, ou apenas estilo, reflete a relação direta entre os locutores, a hierarquia e o grau de proximidade entre eles. De acordo com Bakhtin (2011), o enunciado, com seu estilo e sua composição, é determinado pela relação de valor do locutor com o suposto destinatário. A entonação, por sua vez, é um componente constituinte da palavra e representa o caráter de valor do locutor em relação ao objeto. Voloshinov (1981) apresenta uma perspectiva sociológica

\footnotetext{
${ }^{8}$ As partes constitutivas do enunciado concreto que o diferencia das outras unidades da língua são: i. a alternância de sujeitos falantes; ii. a conclusibilidade, que é composta pela possibilidade de responder, pelo tratamento exaustivo do tema, pela vontade de discurso do locutor ou expressividade e pela escolha do gênero discursivo; iii. a relação do autor com outros enunciados, ou responsividade, e a relação do autor com os outros parceiros da comunicação verbal a partir da direcionalidade do enunciado.
} 
da entonação, discutindo a relação social desse conceito, sempre na fronteira entre o verbal e extraverbal. Para o autor, a entonação mantém as mesmas características que orientam o todo do enunciado, a natureza social, a orientação ao ouvinte e a orientação ao tema.

Sobre a análise realizada, partimos da assertiva de que o MPEF estudado é um programa que privilegia o modelo de formação do especialista técnico, conforme já havia sido investigado por Schäffer (2013) e Souza (2015). De modo geral, o apoio nos preceitos do Círculo Bakhtin/ Voloshinov/Medvedev (BAKHTIN, 2011) permitiu que identificássemos que a direcionalidade dos trabalhos analisados não está voltada para os alunos ou para os professores. Isso indica que os produtos não são pensados a partir de questões relevantes para escola, para os estudantes ou para os docentes. Como exemplo, citamos o trabalho de conclusão 84, que direciona totalmente seu enunciado para um dos orientadores. O autor afirma que a ideia de trabalhar com o Arduino partiu totalmente de um desses docentes. No início da dissertação, ele agradece ao coorientador a partir das seguintes palavras: Agradeço "minha coorientadora e amiga, por me apresentar e me convidar para trabalhar com o Arduino, do qual tive paixão imediata e me rendeu frutos tão valiosos, como essa dissertação.” A partir da entonação utilizada pelo aluno-professor nesse trecho, percebemos que ele não estava preocupado com demandas escolares quando resolveu trabalhar com essa ferramenta tecnológica. A escolha pelo Arduino partiu totalmente da pesquisa do coorientador do trabalho. Já no T19, a demanda para se desenvolver um produto educacional utilizando um dispositivo do tipo CBL (Calculator Based Laboratory) surgiu no momento em que a escola adquiriu um desses materiais. $\mathrm{O}$ autor realizou um trabalho utilizando o $\mathrm{CBL}$ porque a instituição em que trabalhava na época adquiriu um desses dispositivos, e não por ser o melhor equipamento de aquisição de dados para auxiliar no processo de aprendizagem. Essa responsividade às exigências de instituições ou de documentos legais, por outro lado, sempre gera produtos pouco aplicáveis, em geral muito específicos, construídos apenas para suprir essas demandas. Outra situação na qual a escolha do tema partiu de uma exigência externa aparece no T89. Nas palavras do aluno-professor: "[...] foi encaminhada uma carta pela Direção da Escola na qual foi solicitado ao professor de Física, autor da presente dissertação, auxílio para a investigação das possíveis causas do excesso de consumo de energia, bem como a elaboração de um relatório descrevendo tais problemas e encaminhando possíveis soluções." Essa afirmação contraria a própria justificativa fornecida pelo autor para a elaboração do produto, na medida em que ele afirma na Introdução do trabalho que o tema foi escolhido com o objetivo de aproximar a Física da realidade dos estudantes.

Uma situação diferente aparece no T76, no qual o autor não se questiona em nenhum momento sobre a necessidade de desenvolver mais materiais didáticos sobre o conteúdo temático escolhido. Segundo ele, a "escolha do tema Eletrodinâmica deve-se ao fato de que a mesma possibilita experiências e aplicações mais próximas da realidade do aluno e é, na perspectiva da proponente, um assunto interessante e acessível de ser trabalhado". Essa falta de reflexão nos remete ao modelo do especialista técnico, que também parece moldar o discurso do autor do T52, quando recomenda, na apresentação do seu produto educacional para os professores, que esse material didático "foi construído para ser usado diretamente com os seus alunos". Outro aspecto que indica que a concepção racionalista técnica difundida pelo MPEF em questão molda os enunciados dos alunos-professores aparece quando analisamos o gênero discursivo dos textos de apoio. Na grande maioria, os gêneros se assemelham aos utilizados em roteiros tradicionais de laboratório, livros didáticos e manuais e receitas. No trabalho de conclusão 25 
o autor até direciona seu enunciado para os alunos, mas o gênero discursivo, com seu estilo, tema e estrutura, se assemelha muito aos trabalhos existentes na literatura e que foram citados na própria dissertação. Ao invés de propor avanços em relação aos trabalhos existentes, o produto desenvolvido replica o que já havia sendo feito por outros pesquisadores brasileiros. Já o autor do T82, em seu texto de apoio, apenas indica o que o professor deve fazer, sem espaços para maiores reflexões. $\mathrm{O}$ material didático serve apenas como instrumento para ser utilizado passivamente pelo professor. No T32 observamos, novamente, a defesa ingênua da concepção de especialista técnico: a de que o professor precisa de materiais didáticos e de mais conteúdos específicos para que seus alunos efetivem a aprendizagem. Essa concepção permeia todo o desenvolvimento do produto. Nas palavras do autor: "A melhor maneira de prestar uma contribuição neste sentido é qualificando os professores que farão esta introdução. Se eles tiverem domínio conceitual firme e correto, as chances de as crianças aprenderem a ciência de maneira correta, sem dúvida, crescem de maneira considerável".

Uma situação que já havíamos percebido através da síntese quantitativa é o expressivo número de textos de apoio e hipermídias dentro do universo de trabalhos. Atribuímos a preferência por essas naturezas de produto ao fato de existirem seções para publicação desses materiais dentro da própria instituição. A análise discursiva mostra que nossa suposição inicial faz sentido. Observamos em diversas dissertações autores afirmando que o produto desenvolvido seria publicado, antes mesmo da aplicação do projeto. Por exemplo, o autor do T62 afirma na introdução da dissertação: “O material instrucional, produto deste trabalho de mestrado, [...], é apresentado no Apêndice $\mathrm{B}$ e será submetido à publicação na série Textos de Apoio ao Professor de Física". A natureza do produto deve ser a mais adequada para o projeto de desenvolvimento do aluno-professor, e não pode ser primordialmente motivada pela possibilidade de publicações futuras. Ainda sobre o T62, identificamos que o produto desenvolvido é basicamente a tradução de planos de aula disponíveis em um site norte-americano, o que configura plágio na legislação brasileira.

Certamente o aspecto que mais chama a atenção, e que já havia sido sinalizado a partir da análise de similaridades dos trabalhos de conclusão, é a concepção utilitarista no uso dos referenciais teóricos. Ficou muito evidente que os autores utilizam os referenciais apenas porque é uma exigência do contexto institucional. Raras vezes identificamos uma articulação entre o aporte teórico, as questões-foco, o desenvolvimento, a aplicação e a avaliação produto. Mesmo no universo reduzido dos 27 trabalhos analisados, apenas dois se apropriam corretamente das perspectivas teóricas adotadas. No geral, a situação é similar à do T74, no qual o autor, no primeiro parágrafo do capítulo "Referencial Teórico" afirma que o presente trabalho "tem como referencial as teorias de aprendizagem de David Ausubel e Lev Semenovitch Vygotsky, por julgarmos serem as que mais se aproximam da proposta de ensino e aprendizagem aqui apresentada". Quer dizer, primeiro vem a proposta com seus objetivos definidos para posteriormente encontrar um teórico que se adapte a essa proposta. Notamos ainda que esse trecho está em evidência na dissertação, o que indica aceitação do orientador. Com isso, só podemos supor que o docente que orienta o trabalho compartilha da mesma visão utilitarista. Essa concepção ingênua da apropriação teórica, sendo recorrente em quase todos os trabalhos de conclusão analisados, nos leva a creditar ao contexto extraverbal comum - disciplinas e docentes do MPEF - essa difusão errônea observada. Nessa perspectiva, notamos que os autores afirmam utilizar Ausubel se estão desenvolvendo um produto para efetivar aprendizagens, utilizam 
Vygotsky se a implementação prevê interação social, Vergnaud se a preocupação é com o ensino de conceitos, e assim por diante. Em alguns extremos, como é o caso do T15, o autor se "apropria" de Rogers, Vygotsky, Ausubel e Novak, de acordo com a sua necessidade, ou ainda como no T25, onde o autor se embasa em Piaget, Vygotsky, Vergnaud, Ausubel e ainda Paulo Freire. Foi recursiva também a tentativa de associar teoricamente Vygotsky com Ausubel, fruto também do contexto extraverbal comum dos enunciados. Como afirmamos anteriormente, os alunos-professores obrigatoriamente cursaram a disciplina de Teorias de Aprendizagem e Ensino, na qual o livro-texto utilizado foi escrito por um professor orientador que trata Vygotsky como um teórico cognitivista, e que não vê problemas em associar esse referencial à psicologia cognitivista de Ausubel. Essa tentativa de associação teórica é perigosa, pois leva à banalização de diversos conceitos fundamentais da teoria de Vygotsky (PEREIRA; LIMA JÚNIOR, 2014).

Devido a aspectos já mencionados, no geral, concluímos que os textos de apoio de Física clássica desenvolvidos, entre 2002 e 2014, no MPEF estudado não se justificam frente à literatura ou não são aplicáveis para outras escolas. No entanto, dentro dos 27 trabalhos analisados, podemos destacar três que desenvolvem produtos com questões escolares relevantes ou com materiais diferenciados dos habituais. Por exemplo, o autor do T41 desenvolve um produto responsivo às recomendações indicadas pela literatura recente de ensino de Física e seu enunciado direciona-se a escolas de ensino médio em geral. Analisando o produto percebemos um gênero discursivo diferenciado, distante dos tradicionais roteiros de laboratório. A história da Física aparece inserida no texto corrente dos roteiros, e não em caixas isoladas ou notas de rodapé, o que já é um avanço em relação aos livros didáticos encontrados na literatura. Considerando que materiais didáticos com enfoque na história da Física dificilmente são encontrados, principalmente nos livros texto tradicionais, afirmamos que o produto educacional é relevante perante outros materiais e aplicável em escolas de ensino médio.

No T42 também observamos um texto de apoio com um gênero discursivo diferenciado. $\mathrm{O}$ autor faz um relato das suas experiências de sala de aula, destacando os aspectos relevantes para futuros trabalhos de outros professores. $O$ foco do trabalho é um estudo sobre o processo do desenvolvimento cognitivo, através da resolução qualitativa de problemas, à luz da teoria dos campos conceituais de Gèrard Vergnaud. Desde o início da dissertação, percebemos a partir da estrutura do texto e da entonação atribuída, que o autor está apresentando uma forma de resistência às imposições e decisões da instituição em que trabalha. $\mathrm{O}$ aluno-professor coloca que a escola passou por uma grave crise financeira, culminando na redução de carga horária para os professores e aumento no número de alunos por turma. No parágrafo seguinte, o autor coloca que percebe, a partir da sua experiência didática nessa mesma instituição, uma grande dificuldade por parte dos alunos na compreensão dos conceitos de diversos conteúdos da Física. Aparentemente, devido à crise financeira a instituição tomou medidas que prejudicaram aspectos pedagógicos e, com isso, os alunos começaram a apresentar maior dificuldade na compreensão dos conceitos físicos. Além disso, o trabalho de conclusão foi pensado e direcionado aos estudantes de ensino médio, sem contar que o autor se preocupa em justificar as etapas do trabalho de acordo com a teoria dos campos conceituais de Vergnaud.

Outro trabalho de conclusão que se enquadra nesse grupo é o T90, no qual o autor se preocupa em elaborar um produto capaz de atender às especificidades do grupo em que leciona. Esse fato torna o produto relevante, aplicável, e justificável frente aos produtos encontrados na literatura, que não estão voltados para instituições de inclusão social com realidade seme- 
lhante. Fica muito claro também que o autor se preocupa em citar a instituição que trabalha (ONG) e o grupo de estudantes que leciona. A partir da análise da introdução da dissertação podemos concluir que o aluno-professor constrói seu discurso de forma a ser responsivo aos documentos legais que regem a ONG em que atua como docente. Ele justifica a utilização da metodologia de projetos didáticos a partir da estrutura curricular dessa instituição, que faz com que se tenham grupos heterogêneos para se ensinar. No caso analisado a elaboração do produto educacional aproxima-se do modelo do professor reflexivo, que coloca o professor no papel de quem busca pesquisar e refletir e que possui capacidade para resolver criativamente as situações-problema na realização prática de suas pretensões educativas (CONTRERAS, 2002). Nesse modelo, o professor leva em consideração especificidades da realidade que atua, pensando suas ações a partir do meio social e histórico dos seus estudantes. Podemos concluir, a partir do levantamento do contexto extraverbal individual e da história de vida do aluno-professor, que ele já ingressou no MP sendo um professor reflexivo. Apesar disso, ainda encontramos características do modelo do especialista técnico no trabalho de conclusão, principalmente, no que diz respeito ao gênero discursivo do texto de apoio.

\section{Considerações finais}

No presente trabalho fizemos uma análise dos produtos educacionais desenvolvidos por alunos egressos de um MPEF. Inicialmente, analisamos quantitativamente o universo de trabalhos desenvolvidos. Posteriormente, aprofundamos nossa análise com foco nos produtos educacionais de natureza texto de apoio e conteúdo centrado na Física clássica. Essa escolha ocorreu devido à concentração de trabalhos nesse grupo específico. A análise dos textos de apoio, juntamente com as dissertações, foi fundamentada pelas obras do Círculo Bakhtin/ Voloshinov/Medvedev.

Notamos que os produtos educacionais de natureza texto de apoio e hipermídia representam 82 por cento do total de trabalhos desenvolvidos. Atribuímos essa preferência ao fato de existirem na própria instituição duas seções para publicações de trabalhos: uma para textos de apoio e outra para hipermídias. Quando analisamos discursivamente os textos de apoio percebemos que alguns autores já afirmam que vão publicar seu material didático ainda na introdução do trabalho, o que reforça a ideia de que é a possibilidade de publicação que define a natureza de alguns produtos. Em vez disso, consideramos que a natureza do produto desenvolvido deveria estar relacionada com as questões iniciais que norteiam o projeto e que buscam responder a demandas das escolas.

Quando analisamos os referenciais teóricos que embasam os trabalhos de conclusão do MPEF, percebemos que este é o ponto de maior fragilidade do curso. Talvez essa seja a maior influência do modelo racionalista técnico sobre os produtos desenvolvidos. Verificamos, a partir da análise das similaridades e, posteriormente, pela análise discursiva, que o papel do referencial teórico está muito distante da concepção de que deve fundamentar metodologias de ensino e orientar a escolha dos conteúdos além de estabelecer novas formas de avaliação, ou seja, sustentar toda a elaboração do produto educacional (OSTERMANN; REZENDE, 2009). A utilização de referenciais simpáticos aos orientadores e em um viés meramente instrumentalista reforça a significação social e hierárquica do contexto extraverbal dos enunciados. Ou seja, a escolha 
desses aportes teóricos serve de manobra verbal para estreitar a relação entre o aluno-professor, o professor orientador e os avaliadores. A partir da análise discursiva ficou muito evidente que os autores utilizam os referenciais apenas porque é uma exigência do curso. Poucas vezes identificamos uma articulação entre o aporte teórico, as questões-foco, o desenvolvimento, a aplicação e a avaliação do produto. De fato, dos 27 trabalhos de conclusão analisados, apenas dois apropriam-se dos seus teóricos de forma consistente.

Além disso, fizemos a análise discursiva dos textos de apoio de Física clássica para procurar elementos que auxiliassem na busca por respostas para nossas questões de pesquisa. Verificamos que a direcionalidade da maioria dos trabalhos analisados não está voltada para os alunos ou para os professores, indicando que os produtos não partem de questões relevantes para escola, para os estudantes ou para os docentes, mas são projetos responsivos às exigências de instituições ou de documentos legais. Em síntese, com base nos elementos discutidos anteriormente, concluímos que os textos de apoio de Física clássica desenvolvidos no curso de MPEF estudado não se justificam frente aos materiais didáticos disponíveis ou não são aplicáveis em realidades semelhantes ao do público-alvo das propostas. Dentro do universo de 27 trabalhos analisados, podemos destacar apenas três que desenvolveram propostas com questões escolares relevantes ou com materiais diferentes dos habituais. Inclusive detectamos um trabalho de conclusão (T62) que apresenta um produto que é apenas cópia traduzida de um projeto norte-americano. Notamos que o racionalismo técnico propagado pelo MPEF está refletido diretamente no desenvolvimento dos produtos, influenciando na direcionalidade, responsividade, expressividade e gênero discursivo dos trabalhos. A concepção utilitarista no uso dos referenciais teóricos destaca ainda mais esse aspecto tecnicista. Os teóricos são utilizados como "ingredientes de uma receita" que objetiva justificar o trabalho desenvolvido para orientadores e banca avaliadora.

Por fim, gostaríamos de salientar que a pesquisa aqui apresentada expõe resultados importantes, que serão úteis para futuras discussões sobre a qualidade dos produtos educacionais, principalmente, no cenário atual em que a CAPES já sinaliza a criação de um programa Qualis para classificação dos produtos desenvolvidos nos cursos de MP. Acreditamos também ser importante problematizar, a partir dos resultados de nossa pesquisa, se o desenvolvimento de um produto educacional deve realmente ser uma exigência para a conclusão de um curso de MP.

\section{Referências}

BAKHTIN, M. M. Estética da criação verbal. São Paulo: Martins Fontes, 2011.

BORG, I.; GROENEN, P. J. F.; MAIR, P. Applied multidimensional scaling. Berlin: Springer, 2013.

BRASIL. Ministério da Educação. Portaria normativa n 17, de 28 de dezembro de 2009. Dispõe sobre o mestrado profissional no âmbito da Fundação Coordenação de Aperfeiçoamento de Pessoal de Nível Superior - CAPES. Diário Oficial da União, Brasília, n. 248, 2009. Seção 1, p. 20. Disponível em: < http://propg.ufsc.br/files/2010/07/PortariaNormativa-MEC-17-mestrado-profissional1.pdf>. Acesso em: 20 dez. 2016. 
CAPES. Ficha de avaliação de programa de mestrado profissional (2008 -2010).

[Brasília], 2008. Disponível em: <http://www.foprop.org.br/wp-content/uploads/2010/05/ DAV-Ficha-de-avalia\%C3\%A7\%C3\%A3o-Trienal-MP-2008-2010.pdf >.

CAPES. Portaria nº 080, de 16 de dezembro de 1998. Dispõe sobre o reconhecimento dos mestrados profissionais e dá outras providências. Diário Oficial [da] República Federativa do Brasil, Brasília, 11 jan. 1999. Seção 1, p. 14. Disponível em: <https://www.capes.gov.br/ images/stories/download/avaliacao/avaliacao-n/1892015-Portaria-CAPES-080-1998.pdf>. Acesso em: 20 dez. 2016.

CONTRERAS, J. A. A autonomia de professores. São Paulo: Cortez, 2002.

COX, T. F.; COX, M. A. A. Multidimensional scaling. Boca Raton: Chapman \& Hall: CRC, 2001.

GRECA, I. M. Discutindo aspectos metodológicos da pesquisa em ensino de ciências: algumas questões para refletir. Revista Brasileira de Pesquisa em Educação em Ciências, Belo Horizonte, v. 2, n. 1, p. 73-82, 2002. Disponível em: < https://seer.ufmg.br/ index.php/rbpec/article/view/2355/1755>. Acesso em: 21 dez. 2016.

LEVSHINA, N. How to do linguistics with R: data exploration and statistical analysis. Amsterdam: John Benjamins Publishing, 2015.

LIMA JÚNIOR, P. R. M. et al. A apropriação do referencial sociocultural pela pesquisa em ensino de ciências: a relevância do marxismo nas principais obras de Vygotsky. In: ENCONTRO DE PESQUISA EM ENSINO DE FÍSICA, 11., 2008, Curitiba. [Anais...] São Paulo: Sociedade Brasileira de Física, 2008. p. 1-12. Disponível em: <http://hdl.handle. net/10183/31090>. Acesso em: 21 dez. 2016.

MYATT, G. J.; JOHNSON, W. P. Making sense of data I: a practical guide to exploratory data analysis and data mining. Hoboken: John Wiley, 2014.

OSTERMANN, F.; REZENDE, F. Projetos de desenvolvimento e de pesquisa na área de ensino de ciências e matemática: uma reflexão sobre os mestrados profissionais. Caderno Brasileiro de Ensino de Física, Florianópolis, v. 26, n. 1, p. 66-80, 2009. Disponível em: <https:/ /doi.org/10.5007/2175-7941.2009v26n1p66>. Acesso em: 21 dez. 2016.

PEREIRA, A. P.; LIMA JÚNIOR, P. R. M. Implicações da perspectiva de Wertsch para a interpretação da teoria de Vygotsky no ensino de física. Caderno Brasileiro de Ensino de Física, Florianópolis, v. 31, n. 3, p. 518-535, 2014. Disponível em: <https://doi. org/10.5007/2175-7941.2014v31n3p518>. Acesso em: 21 dez. 2016.

QUELHAS, O. L. G.; FARIA FILHO, J. R.; FRANÇA, S. L. B. O mestrado profissional no contexto do sistema de pós-graduação brasileiro. Revista Brasileira de Pós-Graduação, Brasília, v. 2, n. 4, p. 97-104, 2005. Disponível em: <http://ojs.rbpg.capes.gov.br/index.php/ rbpg/article/view/82/78>. Acesso em: 21 dez. 2016. 
REZENDE, F.; OSTERMANN, F. O protagonismo controverso dos mestrados profissionais em ensino de ciências. Ciência \& Educação, Bauru, v. 21, n. 3, p. 543-558, 2015. Disponível em: <https://doi.org/10.1590/1516-731320150030002>. Acesso em: 21 dez. 2016.

SCHÄFER, E. D. A. Impacto do mestrado profissional em ensino de física da UFRGS na prática docente: um estudo de caso. 2013. 338 f. Tese (Doutorado) - Instituto de Física, Universidade Federal do Rio Grande do Sul, Porto Alegre, 2013.

SCHÄFER, E. D. A.; OSTERMANN, F. O impacto de um mestrado profissional em ensino de física na prática docente de seus alunos: uma análise bakhtiniana sobre os saberes profissionais. Ensaio: pesquisa em educação em ciências, Belo Horizonte, v. 15, n. 2 , p. 87-103, 2013. Disponível em: < http://www.scielo.br/pdf/epec/v15n2/1983-2117epec-15-02-00087.pdf>. Acesso em: 21 dez. 2016.

SOUZA, J. Apropriação discursiva de modelos de formação docente em trabalhos de conclusão de um mestrado profissional em ensino de física. 2015. 119 f. Dissertação (Mestrado) - Instituto de Física, Universidade Federal do Rio Grande do Sul, Porto Alegre, 2015.

VOLOSHINOV, V. N. La structure de l'énoncé. In: TODOROV, T. (Ed.). Mikhaïl

Bakhtine: le principe dialogique suivi de écrits du cercle de Bakhtine. Paris: Seuil, 1981. p. 287-316. Tradução de Ana Vaz para fins didáticos.

Artigo recebido em 21/04/2016. Aceito em 31/07/2016.

Endereço para correspondência: Instituto de Física, UFRGS, Secretaria do PPGEnFis, Avenida Bento Gonçalves, 9.500, Caixa Postal 15051, CEP 91501-970, Porto Alegre, RS, Brasil. 